\title{
Storage potential of fresh 'Manzanillo' olives
}

\author{
Adel A. Kader a George D. Nanos
}

\begin{abstract}
Ideal preprocessing storage for fresh, green 'Manzanillo' olives is at $41^{\circ}$ to $45^{\circ} \mathrm{F}\left(5^{\circ}\right.$ to $\left.7.5^{\circ} \mathrm{C}\right)$ and 90 to $95 \%$ relative humidity. Under these conditions, the olives can be stored for 6 to 8 weeks in air, or 9 to 12 weeks in a $2 \%$ oxygen atmosphere with no significant loss in quality.
\end{abstract}

The olive is an important commercially produced tree fruit in California. When ripe, its fresh fruit is a dark purple-black and inedible. Once processed, it can be sold as olive oil or canned olives. Almost all the California production is canned as black or green ripe olives. Olives intended for this purpose are picked in the mature-green to partially ripe stages from lateSeptember to early November.

Because so many olives are harvested during this short period, many must be stored in brine until they can be processed. The problem of how to eventually dispose of this brine as wastewater could be partially resolved by storing the fresh olives without brine. To evaluate the potential of such a method, we investigated the responses of fresh olives to various storage temperatures and atmospheres.

During the 1987 and 1988 seasons, we obtained 'Manzanillo' olives from the Lindsay Olive Growers Association (Lindsay, California). Random lots were sorted and matched for the different treatments. We measured respiration and ethylene production rates in the outlets of 2-liter glass jars (each containing approximately $400 \mathrm{~g}$ of olives) that were ventilated with air or the

\author{
- Eduardo L. Kerbel
}

desired gas mixtures in a continuous flowthrough system. For quality evaluation, we measured skin color and flesh firmness (measured with a UC Fruit Firmness Tester with a $1.5 \mathrm{~mm}$ tip). The olives were also evaluated for incidence and severity of physiological disorders, including chilling injury (surface and internal browning) and surface pitting and spotting (nailhead).

\section{Respiration, ethylene production}

Black olives showed a high initial respiration rate, which declined with time at $68^{\circ} \mathrm{F}$, but was always higher than that of green olives. This difference was reflected in the faster deterioration of black olives compared to green olives. Ethylene production by black olives increased significantly after 3 days at $68^{\circ} \mathrm{F}$, reaching a maximum after about 12 days. In contrast, green olives showed a rise in ethylene production after about 20 days at $68^{\circ} \mathrm{F}$, reaching a maximum after about 25 days. The maximum levels of ethylene production reached by black and green olives were about equal, and were lower than 0.5 microliter per kilogram per hour.

\section{Low temperatures}

Storing 'Manzanillo' olives at $32^{\circ}$ and $36^{\circ} \mathrm{F}$ caused chilling injury after 2 and 5 weeks, respectively, and fast deterioration upon transfer to higher temperatures. The main symptoms of chilling injury were internal and surface browning. Internal browning began around the pit and radiated outward toward the skin as time progressed. Surface browning appeared to follow the development of internal browning; it may indicate a more advanced stage of chilling injury. Olives stored for as long as 12 weeks at $41^{\circ}$,

TABLE 1. Effects of various storage atmospheres and temperatures on the flesh firmness and skin color of 'Manzanillo' olives

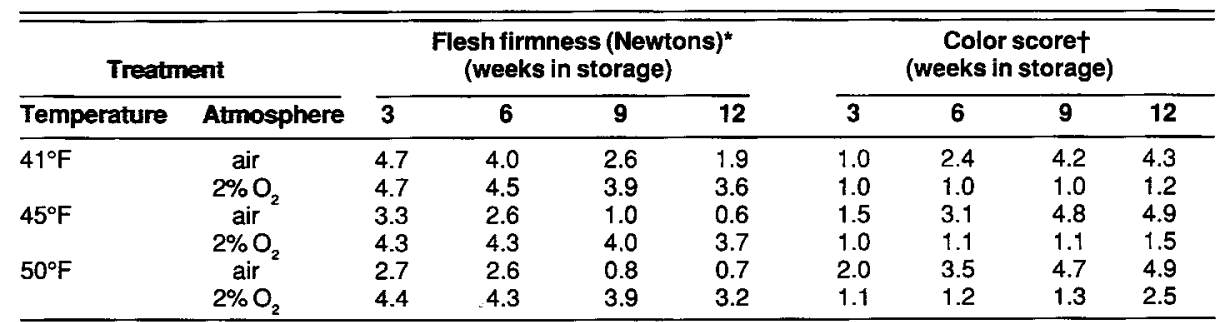

"Initial flesh firmness $=5.6$ Newtons ( 1 pound force $=4.448$ Newtons). tInitial color score $=1.0$; see color photo for scoring system.
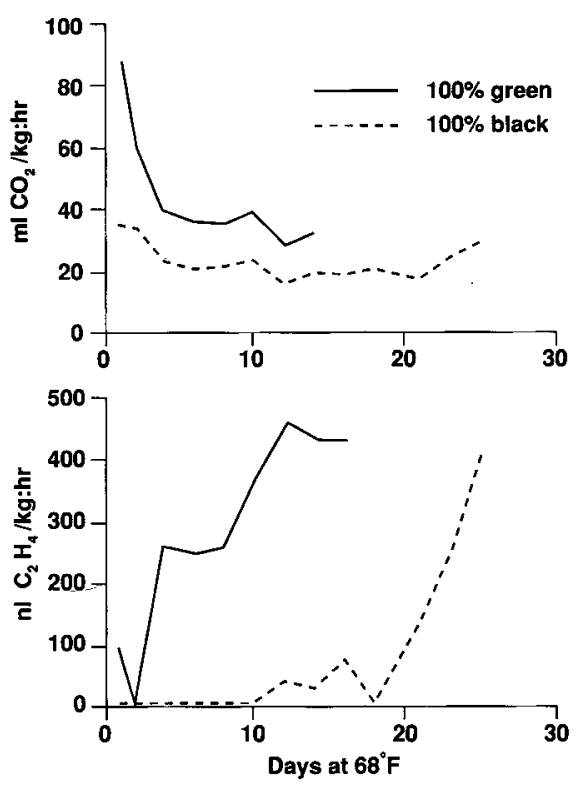

Fig. 1. Respiration and ethylene production rates of green and black 'Manzanillo' olives kept at $68^{\circ} \mathrm{F}$ for 25 days.
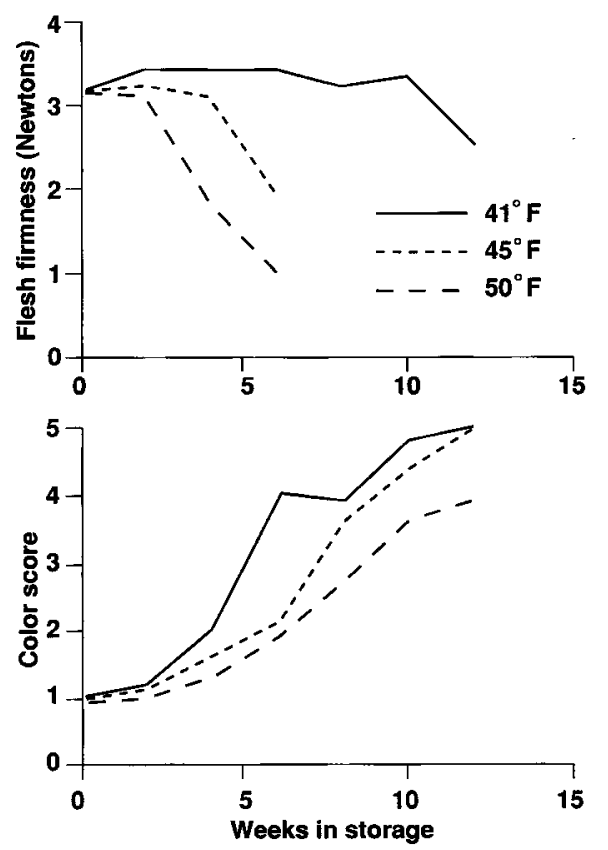

Fig. 2. Changes in flesh firmness ( $1 \mathrm{lb}$ force $=$ 4.448 Newtons) and skin color of 'Manzanillo' olives during storage at three temperatures for 12 weeks (photo on back cover shows color rating samples).

CALIFORNIA AGRICULTURE, MAY-JUNE 1990 


\section{Olives (continued from page 23)}

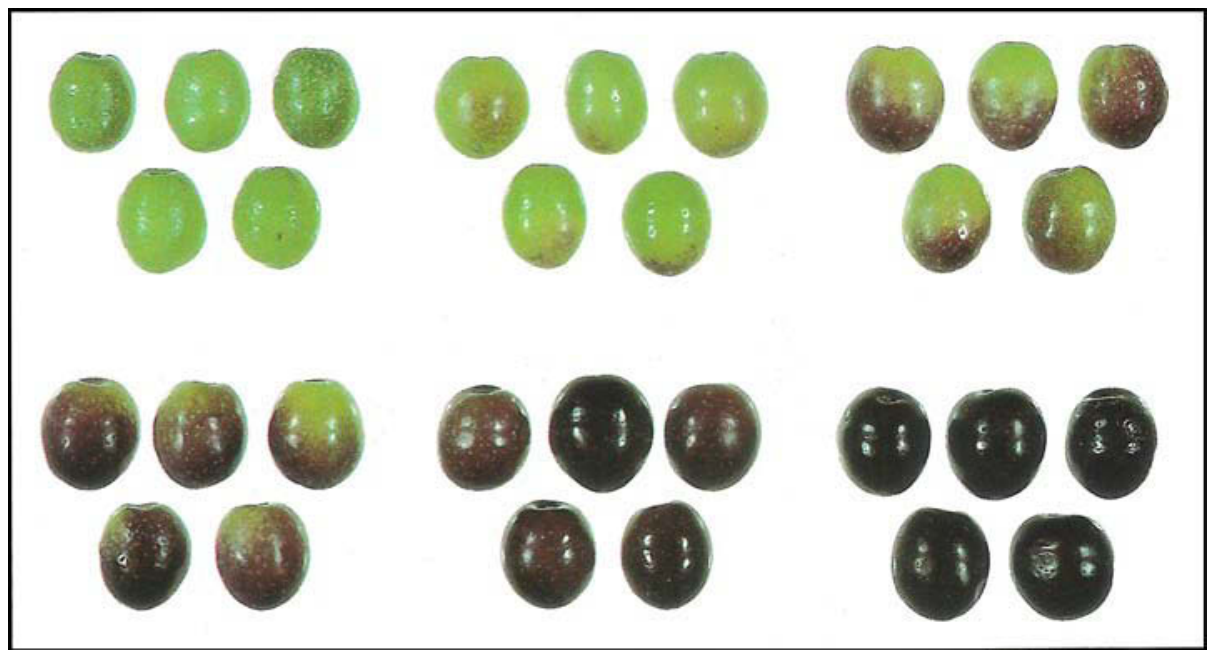

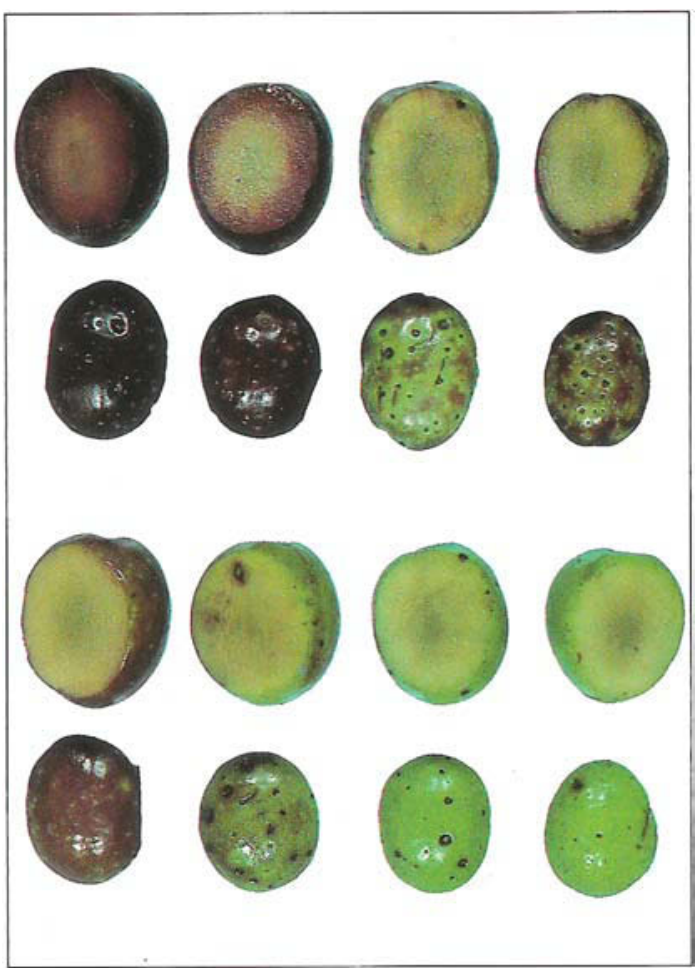

Olives stored for 6 weeks in air (top two rows) were much more likely to develop nailhead symptoms than those stored in a $2 \%$ oxygen atmosphere (bottom two rows). $45^{\circ}$, or $50^{\circ} \mathrm{F}$ in air showed no symptoms of chilling injury. Based on these and previous observations, we recommend avoiding storage temperatures below $41^{\circ} \mathrm{F}$.

Retention of flesh firmness was greatly influenced by storage temperatures (fig. 2). Olives retained satisfactorily firm flesh for 12 weeks at $41^{\circ} \mathrm{F}, 6$ weeks at $45^{\circ} \mathrm{F}$, or 4 weeks at $50^{\circ} \mathrm{F}$. Skin color changed from green to black more quickly at the higher temperatures (fig. 2). The major concern during olive storage is maintaining flesh firmness and green color. Therefore, we recommend storage at $41^{\circ} \mathrm{F}$.

Nailhead, a disorder characterized by surface pitting and spotting, was observed mainly in olives stored at $50^{\circ} \mathrm{F}$ for 6 weeks or more. The pitting results from the death and collapse of epidermal cells, which creates air pockets underneath the fruit skin.

\section{Controlled atmospheres}

During the 1987 season, we stored 'Manzanillo' olives at $50^{\circ} \mathrm{F}$ in air enriched with 0,5 , 10 , or $15 \%$ carbon dioxide. After 6 weeks' storage, olives exposed to each of the carbon dioxide concentrations developed physiological injury. Carbon dioxide injury, expressed as internal browning, was followed by increased decay. We conclude that levels
Six color classes are used for 'Manzanillo' olives. Left to right, top row: classes $1 \mathrm{a}, 1 \mathrm{~b}$, and 2 ; bottom row: classes 3,4 , and 5 .

at or above $5 \%$ carbon dioxide must be avoided during storage of fresh olives.

We also tested the effects of low oxygen levels as a supplement to low temperatures to delay fruit ripening. Olives were kept for as long as 12 weeks at $41^{\circ}, 45^{\circ}$, and $50^{\circ} \mathrm{F}$ in air or in $2 \%$ oxygen ( $98 \%$ nitrogen) during the 1988 season. Olives in the $2 \%$ oxygen treatment retained their firm flesh and green color almost at initial levels (table 1). Some olives kept for 12 weeks in $2 \%$ oxygen at $41^{\circ} \mathrm{F}$ exhibited slight symptoms of chilling injury, but this did not reduce their overall quality. Storage at $45^{\circ} \mathrm{F}$ in $2 \%$ oxygen extended olive storage life to 9 weeks.

\section{Conclusions}

Storage temperatures below $41^{\circ} \mathrm{F}$ must be avoided for green 'Manzanillo' olives because they are susceptible to chilling injury. Green 'Manzanillo' olives can be stored in air at $41^{\circ}, 45^{\circ}$, or $50^{\circ} \mathrm{F}$ for 8,6 , or 4 weeks, respectively, before chilling injury or excessive ripening occur. The olives can be stored in $2 \%$ oxygen at $41^{\circ}$ and $45^{\circ} \mathrm{F}$ for about 12 and 9 weeks, respectively, without any significant quality loss. The relative humidity during storage should be between 90 and 95\% to minimize water loss. Exposure to $5 \%$ or more carbon dioxide should be avoided, since it can cause physiological injury to the olives.

Adel A. Kader is Professor and Pomologist, and George D. Nanos is Research Assistant, Department of Pomology, University of California, Davis. Eduardo L. Kerbel is Assistant Professor, currently with the University of Illinois, Urbana. The authors thank the Lindsay Olive Growers Association for financial support of this research. Photographs by Don Edwards, Department of Pomology, UC Davis. 